\title{
Enhanced Antitumor Effect of Radiation in Combination with Heat-Sensitive Liposome-Encapsulated Drug and Hyperthermia on Murine Tumors
}

\author{
Chelvi P. TAMIZ and Ralhan RANJU* \\ Department of Biochemistry, All India Institute of Medical Sciences, \\ Ansari Nagar, New Delhi 110029, India
}

(Received April 22, 1995)

\begin{abstract}
Summary Adjuvant hyperthermia enhances the response of melanoma to irradiation or antineoplastic drugs. Radiation in combination with a targeted drug delivery system combining a thermosensitive liposome-encapsulated antitumor drug with hyperthermia may thus result in enhancement of therapeutic efficacy for more effective management of melanoma. The present study was based on this rationale. The therapeutic effect of radiation alone, or in combination with thermosensitive liposome-encapsulated melphalan and hyperthermia, was determined on B16F10 murine melanoma transplanted into C57B1/6 mice. This multimodality regimen resulted in marked enhancement of the antitumor efficacy in treated animals, as determined by significant tumor growth regression $(p<0.001)$ and prolongation of survival, compared with the level of enhancement seen in animals receiving single-modality treatment. The results suggest that radiothermochemotherapy using radiation in combination with heat-mediated selective delivery of liposomal melphalan to tumor tissue would result in more effective management of melanoma.
\end{abstract}

Key Words: chemotherapy, radiation, heat-sensitive liposomes, melanoma, melphalan

Malignant melanoma has been considered to be a radioresistant tumor and is conventionally treated by surgery, immunotherapy, or chemotherapy, alone or in combination with hyperthermia [1]. However, the loco-regional control and survival rates in patients with metastatic melanoma remain poor [2]. Radiation therapy has been tried for the management of metastatic malignant melanoma

*To whom correspondence should be addressed.

Abbreviations: M-ThLip, melphalan-entrapping thermosensitive liposomes; HT, hyperthermia; CT, chemotherapy; TDD, targeted drug delivery; PBS, phosphate-buffered saline 
[3-14]. The clinical use of radiation therapy in the treatment of melanoma is limited to palliation of metastatic or recurrent disease. In vitro studies have shown that melanoma cells have a high capacity for repair of sublethal radiation damage $[15,16]$. The use of a higher radiation dose for overcoming the resistance of some of the melanoma cells to irradiation is based on this rationale of high capacity of melanoma cells for the repair of sublethal damage. Several clinical studies suggest that melanoma may be more radioresponsive if large doses per fraction are utilized $[10,17]$.

The use of hyperthermia as an adjunct to radiotherapy has been reported to have an additive and/or synergistic effect [18]. Adjuvant hyperthermia enhances the response of human melanoma to irradiation and diminishes the importance of the radiation-dose size $[19,20]$. Several clinical studies have also demonstrated an increase in the local-regional control rate of melanoma treated with radiation and hyperthermia compared with that rate found with radiation alone $[14,20,21]$. Hyperthermia has also been shown to enhance the therapeutic efficacy of several antitumor drugs [22, 23].

Effective chemotherapy for metastatic melanoma remains an elusive goal. Hence, new strategies are being tried to improve the therapeutic index of antitumor drugs for management of melanoma. Several clinical trials using combination chemotherapy [24-28] particularly the BOLD and related regimens (bleomycin, vincristine, CCNU, and dacarbazine) have been reported [29-32]. In recent years there has been a renewal of interest in the use of hyperthermia as a treatment modality for melanoma therapy, and research has focused on treatment with the combination of hyperthermia and drugs [33, 34]. Raaphorst and Azzam [35] reported the response of transformed and normal cell lines to antimelanin compounds, 2- and 4-hydroxyanisole, alone or combined with hyperthermia or radiation. Treatment of B16F10 melanoma with the combination of hyperthermia, melphalan, and CCNU resulted in progressive delay in tumor growth, reduced metastases, and diminution of proliferative capacity [36]. As antitumor drugs fail to discriminate between normal and target tissues, any approach enabling a chemotherapeutic agent to reach its target in a selective manner would represent a major advancement in cancer chemotherapy.

Recent work has shown that liposomes may fulfill this requirement. The goal of using liposomes as a carrier system involves delivery of a high concentration of drug at the target site where beneficial effects may occur and a low drug concentration at other sites where adverse side effects may occur. In the present study we prepared thermosensitive liposomes for encapsulation of melphalan and determined the antitumor efficacy of liposomal melphalan in combination with hyperthermia and radiation on murine melanoma with the aim of developing more effective therapeutic protocols for management of melanoma. 


\section{MATERIALS AND METHODS}

Chemicals. Dipalmitoyl phosphatidyl choline (DPPC), distearoyl phosphatidyl choline (DSPC), and Sepharose-4B were obtained from Sigma Chemicals Co. (St. Louis, MO). The purity of the lipids was checked by thin-layer chromatography on silica gel plates. Melphalan was obtained from Wellcome Foundation Ltd., Londra Pomezia (Rome). It was dissolved in phosphate-buffered saline $(0.2 \mathrm{M}, \mathrm{pH}$ 7.2 , PBS) at a concentration of $3 \mathrm{mg} / \mathrm{ml}$ just before use. All other chemicals used were analytical grade purchased from SISCO Research Laboratories, Bombay, India. The organic solvents used were HPLC grade purchased from Qualigens, India.

Animals and tumors. C57B1/6 mice were purchased from National Institute of Immunology (New Delhi, India), and from the National Institute of Nutrition, Hyderabad. B16F10 murine melanoma was a gift from Dr. Vincent Hearing, National Institutes of Health, (Bethesda, MD). Melanocytes $\left(3 \times 10^{6}\right.$ in $50 \mu 1$ PBS) were injected subcutaneously (s.c) into the shank region of 10- to 12-week-old male C57B1/6 mice. The tumors were allowed to develop for 15 to 20 days. Tumor size was determined by measuring the tumor volume according to the formula $V=$ $\pi / 6 \times \mathrm{D} 1 \times \mathrm{D} 2 \times \mathrm{D} 3$, where "D1, D2, D3" represent three orthogonal diameters.

Preparation of small unilamellar vesicles. Small unilamellar vesicles (SUVs) were prepared by the method of Kirby and Gregoriadis [37]. Briefly, DPPC and DSPC at a molar ratio of $9: 1$ were dissolved in chloroform : methanol $(2: 1 \mathrm{v} / \mathrm{v})$, at $25 \mathrm{mg}$ of total lipid $/ \mathrm{ml}$ of organic solvents, evaporated under reduced pressure, and dried by overnight desiccation. The lipid film was then suspended in $200 \mu 1$ of distilled water and sonicated with a probe-type sonicator (Sonicator W-385, Heat Systems Ultrasonics Inc., Farmingdale, NY) at $100 \mathrm{~mA}, 1$ pulse/s for $30 \mathrm{~min}$ with intermittent cooling. Melphalan was suspended in PBS $(3 \mathrm{mg} / \mathrm{ml})$, flash frozen, and lyophilized. Distilled water $(0.2 \mathrm{ml})$ was added and vortexed for $20 \mathrm{~min}$. The volume was then made up to $2 \mathrm{ml}$, and the material was centrifuged at $105,000 \times \mathrm{g}$ for $1 \mathrm{~h}$ at $4^{\circ} \mathrm{C}$. The liposomal pellet was suspended in $0.5 \mathrm{M} \mathrm{NaCl}$, and the nonentrapped melphalan was removed by passing the liposomal suspension through a Sepharose-4B column. Alternatively liposomes were prepared by use of a Liposomat (Dianoram, Germany). Liposomat usage helped in the preparation of homogeneous, stable, small unilamellar vesicles of a defined, uniform size. The phosphorus content of the liposomal preparation was estimated by Bartlett's method [38].

Hyperthermia treatment. Hyperthermic treatment was given by immersing the tumor-bearing leg of animals in a circulating water bath maintained at $42 \pm$ $0.2^{\circ} \mathrm{C}$ and equipped with specially designed Plexiglas holders by use of which only the tumor-bearing leg was in contact with the hot water. The mice were air cooled during the heat treatment. The temperature in the center of the tumor was measured with a small thermistor probe having a $0.8 \mathrm{~mm}$ diameter (Tastomed, $\mathrm{P}$.

Vol. 19, No. 3, 1995 
Braun Electronics, Frankfurt, Germany). The tumor temperature rose within $5 \mathrm{~min}$ from 34 to $43^{\circ} \mathrm{C}$, whereas the rectal temperature increased only from 37 to $39^{\circ} \mathrm{C}$ and varied by $0.5^{\circ} \mathrm{C}$ during the heating.

Radiation treatment. Irradiation was given with a Theratron 60, GS-900 machine (total dose of $150 \mathrm{cGy}$ per treatment). All treatments were administered to nonanesthetized mice placed in a Plexiglas box. Their tumor-bearing legs were exposed and tumors only were irradiated while the remainder of the animal was being shielded by $1 \mathrm{~cm}$ of lead.

In vivo radiothermochemotherapy studies. Experiments were performed on day 14-15 after inoculation of B16F 10 murine melanocytes into $\mathrm{C} 57 \mathrm{~B} 1 / 6$ mice. On day 14-15 animals were randomized into the following groups (6 mice/group): untreated controls, C; radiation ( $150 \mathrm{cGy})$, RT; radiation ( $150 \mathrm{cGy})$ with melphalan $\left(3 \mathrm{mg} / \mathrm{kg}\right.$ body wt), $\mathrm{RT}+\mathrm{CT}$; radiation $(150 \mathrm{cGy})$ with hyperthermia $\left(42^{\circ} \mathrm{C}, 1\right.$ $\mathrm{h})$, RT $+\mathrm{HT}$; and radiation (150 cGy) in combination with thermosensitive liposome-encapsulated melphalan and hyperthermia $\left(42^{\circ} \mathrm{C}, 1 \mathrm{~h}\right),(\mathrm{M}-\mathrm{ThLip}+\mathrm{RT}+$ HT). The amount of melphalan entrapped in liposomes was equivalent to that used in the group receiving free drug in solution. Initial tumor dimensions were recorded before commencement of the treatment. For radiothermochemotherapy studies radiation was given prior to thermochemotherapy. For thermochemotherapy $250 \mu \mathrm{l}$ of liposomal suspension ( $3.75 \mu \mathrm{mol}$ phospholipid containing $60 \mu \mathrm{g}$ melphalan) was injected into a tail vein of the mice just before commencement of the hyperthermic treatment. The mice that received hyperthermia alone, or in combination with an injection of thermosensitive liposome-encapsulated melphalan as mentioned above, were transferred to Plexiglas holders for hyperthermic treatment. Hyperthermia was given within $30 \mathrm{~s}$ of injection of the thermosensitive liposome-encapsulated melphalan. The plasma half life of melphalan is $25 \mathrm{~min}$. Hence heat and drug-loaded liposomes were administered simultaneously for maximum potentiation of the antitumor effect. In the groups receiving hyperthermia in combination with radiation, hyperthermia was given within $10 \mathrm{~min}$ of radiation treatment, with the aim of killing the radioresistant population of cells. Heating was continued for $1 \mathrm{~h}$. Thereafter, tumor volume was measured. The treatments were repeated on alternate days six times over a period of about 2 weeks. Tumor volume was measured daily for a period of 1 month, and the survival of the animals was monitored for 3 months. Each experiment was repeated three times.

Statistical analyses. Differences in medians among treatment regimens within each group were tested by the Kruskal-Wallis test [39]. Multiple comparisons were performed when significant differences were found.

\section{RESULTS}

\section{In vivo radiothermochemotherapy studies}

Thermosensitive, small, unilamellar vesicles prepared from synthetic lipids, 
DPPC : DSPC in 9:1 molar ratio, and having a gel-to-liquid crystalline phase transition at $42^{\circ} \mathrm{C}$ (determined by differential scanning calorimetry, data not shown) were used for encapsulation of melphalan. The effect of in vivo radiothermochemotherapy on tumor growth regression was studied. The variation in tumor

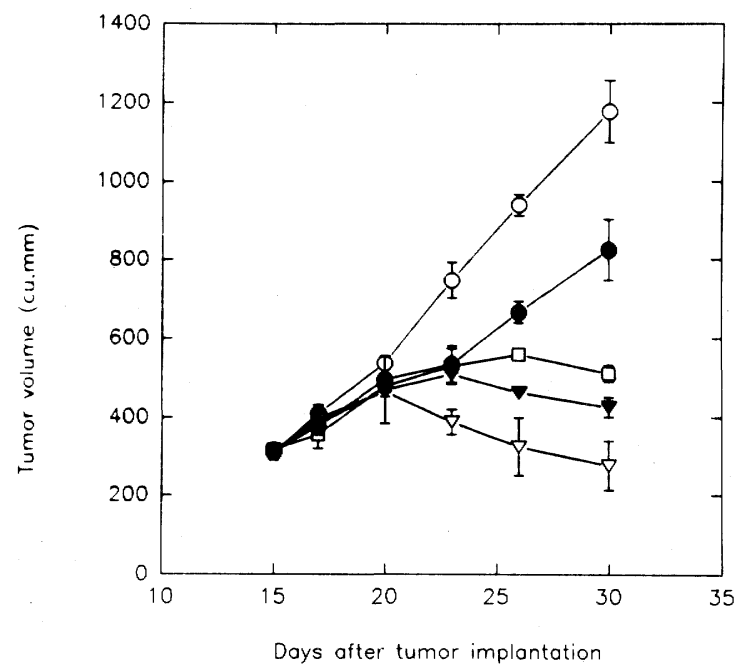

Fig. 1. Tumor regression studies. Changes in melanoma tumor volume with different treatments expressed as the mean \pm SE. Each group consisted of 6 animals, and each experiment was repeated thrice. $O$, control; $\bullet$, radiotherapy at $900 \mathrm{cGy} ; \mathbf{\nabla}$, radiation and hyperthermic treatment at $43^{\circ} \mathrm{C}$ for $1 \mathrm{~h} ; \square$, chemotherapy (melphalan in solution, $3 \mathrm{mg} / \mathrm{ml}$ ) and radiotherapy; $\nabla$, thermosensitive liposome-encapsulated melphalan, radiation, and hyperthermia.

Table 1. Thermoradiochemotherapy studies on murine melanomas.

\begin{tabular}{cccccc}
\hline & \multicolumn{5}{c}{ Tumor volume mean \pm SE (cu.mm)* } \\
\cline { 2 - 6 } $\begin{array}{c}\text { Days after } \\
\text { tumor } \\
\text { implantation }\end{array}$ & $\begin{array}{c}\text { Control } \\
\text { (C) }\end{array}$ & $\begin{array}{c}\text { Radiation } \\
\text { (RT) }\end{array}$ & $\begin{array}{c}\text { Radiation } \\
+ \\
\text { hyperthermia } \\
\text { (RT }+ \text { HT) }\end{array}$ & $\begin{array}{c}\text { Radiation } \\
+ \\
\text { chemotherapy } \\
(\mathrm{RT}+\mathrm{CT})\end{array}$ & $\begin{array}{c}\text { M-ThLip } \\
+ \text { RT } \\
+ \text { HT }\end{array}$ \\
\hline 15 & $309 \pm 13$ & $316 \pm 21$ & $316 \pm 14$ & $317 \pm 27$ & $312 \pm 12$ \\
17 & $410 \pm 22$ & $378 \pm 21$ & $384 \pm 35$ & $356 \pm 21$ & $398 \pm 26$ \\
20 & $538 \pm 16$ & $497 \pm 19$ & $470 \pm 28$ & $480 \pm 13$ & $470 \pm 86$ \\
23 & $747 \pm 46$ & $535 \pm 32$ & $510 \pm 45$ & $531 \pm 29$ & $388 \pm 22$ \\
26 & $939 \pm 27$ & $666 \pm 75$ & $463 \pm 16$ & $560 \pm 25$ & $325 \pm 14$ \\
30 & $1,178 \pm 78$ & $826 \pm 64$ & $426 \pm 22$ & $512 \pm 17$ & $276 \pm 25$ \\
\hline
\end{tabular}

*Six animals/group. Each experiment was repeated thrice (mean \pm SE). Statistical analyses: Kruskal-Wallis test. Determination of level of significance in tumor volume of animals in different groups. Day 30: C, RT, RT $+\mathrm{HT}, \mathrm{CT}+\mathrm{RT}, \mathrm{M}-\mathrm{ThLip}+\mathrm{HT}+\mathrm{RT} p<0.001$. Inter group variation. Day 30: C/RT $+\mathrm{HT} / \mathrm{CT}+\mathrm{RT} / \mathrm{M}-\mathrm{ThLip}+\mathrm{RT}+\mathrm{HT} p<0.001, \mathrm{RT} / \mathrm{RT}+$ HT $p<0.001, \mathrm{RT} / \mathrm{RT}+\mathrm{CT} p<0.001, \mathrm{RT}+\mathrm{HT} / \mathrm{CT}+\mathrm{RT}$ N.S., $\mathrm{RT}+\mathrm{HT} / \mathrm{M}-\mathrm{ThLip}+\mathrm{HT}+$ $\mathrm{RT} p<0.01, \mathrm{CT}+\mathrm{RT} / \mathrm{M}-\mathrm{ThLip}+\mathrm{HT}+\mathrm{RT} p<0.01$.

Vol. 19, No. 3, 1995 
volume with different treatments with respect to time after tumor implantation is shown in Fig. 1. The results of statistical analysis of variation in tumor volume (mean $\pm \mathrm{SE}$ ) with time (days after tumor implantation) of mice subjected to different treatments are shown in Table 1. A progressive increase in tumor volume from $309 \pm 12.5 \mathrm{cu} . \mathrm{mm}$ on day 15 to $538 \pm 15.6 \mathrm{cu}$.mm on day 20 and to $1,178 \pm 78$ cu.mm by day 30 was observed in the control group of animals that did not receive any treatment. In the radiation $(900 \mathrm{cGy})$-treated group, there was a slower increase in tumor volume. A tumor-growth delay of 3 days was observed, in comparison with the control, for the animals to reach a tumor volume of $535 \pm 31.8$ cu.mm. A similar delay was observed in animals receiving a combination of radiation and hyperthermia, or radiation and free drug, melphalan, in solution. In contrast, animals receiving the combination of radiation, hyperthermia and temperature sensitive liposome-encapsulated melphalan showed significant tumor growth delay compared with animals receiving thermochemotherapy or thermoradiotherapy. Animals treated with a combination of radiation followed by hyperthermia showed a progressive decline in tumor volume to $426 \pm 21.5 \mathrm{cu} . \mathrm{mm}$ by day 30. A similar decrease in tumor volume was also observed in animals receiving the combination of radiation and free melphalan in solution. No significant difference in tumor growth regression pattern was observed in animals receiving radiation in combination with hyperthermia or chemotherapy. A significant decrease in tumor volume $(276 \pm 24.6 \mathrm{cu} . \mathrm{mm}$ on day $30, p<0.001)$ was

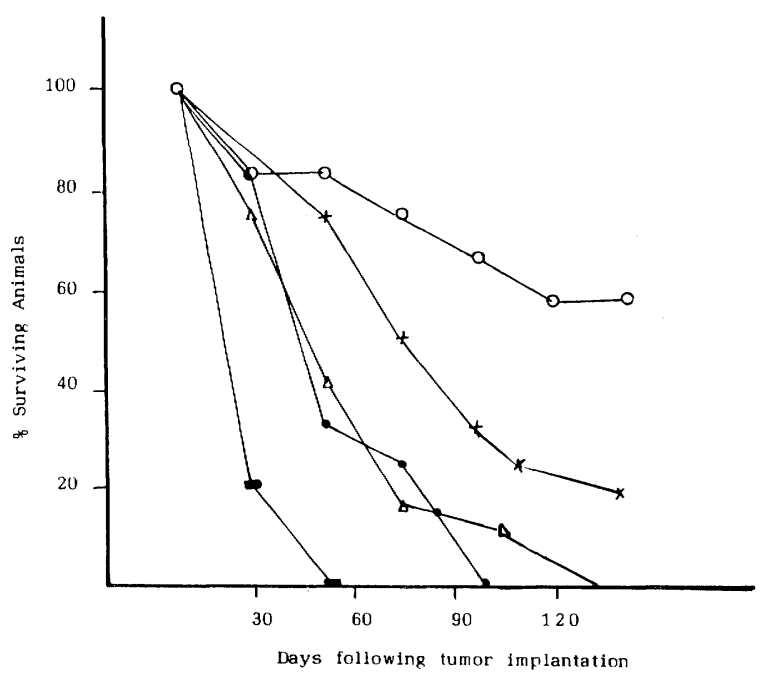

Fig. 2. Survival studies on tumor growth-regressed animals. Survival curves were derived from groups of 18 animals/group. $\mathbf{\square}$, control; $\boldsymbol{0}$, radiotherapy at $900 \mathrm{cGy} ; \triangle$, chemotherapy (melphalan in solution, $3 \mathrm{mg} / \mathrm{kg}$ body wt) and radiation; $\times$, hyperthermic treatment $\left(43^{\circ} \mathrm{C}, 1 \mathrm{~h}\right)$ and radiation; $\bigcirc$, thermosensitive liposome-encapsulated melphalan, radiation, and hyperthermia. 
observed in mice treated with the combination of radiation, hyperthermia and thermosensitive liposome-encapsulated melphalan.

\section{Survival studies}

The percentage of survival of tumor-bearing animals subjected to the different treatments is shown in Fig. 2. In the control untreated group of tumor-bearing animals, $50 \%$ of the animals died by day 30 ; all the animals in this group were dead by day 55. A similar survival rate was observed in radiation therapy and radiochemotherapy groups till day 85 . A marked improvement in survival rate was observed in the animals treated with the combination of radiation and hyperthermia. Over $40 \%$ of animals in this treatment group survived till day 75 , and $20 \%$ of the animals were still alive on day 115 . However, the most significant prolongation in survival rate was observed in the multimodality-treated group receiving radiation in combination with thermosensitive liposome-encapsulated melphalan and hyperthermia. Over $60 \%$ of animals in this treatment group were still alive on day 100. No recurrence of secondary tumors was observed up to 120 days, and no tumor metastasis was observed.

\section{DISCUSSION}

Radiation therapy has been the most commonly used modality for treatment of locally advanced non-resectable malignancies [40], and new strategies are being explored for augmenting the antitumor effects of radiation. Combined modality therapy using radiation in combination with hyperthermia [41] or chemotherapeutic agents [42] has shown great promise in the clinic. The rationale for this combined modality approach is based on two facts: (1) some antitumor drugs are cytotoxically interactive with radiation and hyperthermia [43], and (2) hyperthermia $[44,45]$ and some antineoplastic agents $[46,47]$ can effectively attack radioresistant subpopulations of tumor cells in $\mathrm{G}_{1}$ and $\mathrm{G}_{2} / \mathrm{M}$-phases of the cell cycle under the conditions of hypoxia at low $\mathrm{pH}$.

In vivo radiothermochemotherapy studies presented herein were designed based on this rationale. In the multimodality approach, radiation therapy was used to destroy the radiosensitive population of melanocytes, cells in the S-phase of the cell cycle. The radioresistant population of tumor cells was subjected to thermochemotherapy using thermosensitive liposome-encapsulated melphalan in combination with hyperthermia. Local hyperthermic treatment of tumors would result in preferential targeting of thermosensitive liposomes to the tumors [48]. A heatmediated increase in tumor blood flow may result in increased uptake of drugloaded liposomes by tumor tissue [47]. In the heated tumor tissue, the temperature-sensitive, drug-loaded liposomes undergo gel-liquid phase transition, resulting in increased permeability of the liposomal membrane and selective release of the drug, thereby causing enhanced cell killing [49]. Furthermore, thermosensitive liposomal encapsulation of melphalan would also prevent release

Vol. 19, No. 3, 1995 
of the drug in unheated normal tissues, thereby reducing normal tissue toxicity. The in vivo studies presented herein clearly show that radiation treatment resulted in partial tumor growth regression only. The combination of radiation with hyperthermia or melphalan led to a significant reduction in tumor volume $(p<$ $0.001)$ compared with radiation alone. The tumor-bearing animals receiving multimodality therapy involving radiation followed by drug-loaded liposomes and localized hyperthermia showed significant tumor regression $(p<0.001)$ compared with the animals treated with the combination of radiation with hyperthermia or free drug, melphalan. The mice receiving this multimodality therapy also showed the maximum prolongation of survival; i.e., over $60 \%$ of the treated animals were alive more than 100 days after the tumor inoculation.

Hyperthermia-mediated, targeted drug delivery of cisplatin or methotrexate encapsulated in temperature-sensitive liposomes to murine tumors has been shown to result in similar enhancement of antitumor efficacy [49-51]. Overgaard et al. [52] demonstrated synergistic interaction between hyperthermia and cisplatin given in various schedules as an adjuvant and radiation treatment of solid tumors in vivo.

In conclusion, our data show greater tumor growth regression and prolonged survival produced by the combination of radiation, thermosensitive liposomeencapsulated melphalan, and hyperthermia, suggesting that this multimodality approach will be useful for management of melanoma.

This work was supported by a research grant from the Indian Council of Medical Research, India. Tamiz Chelvi P. is a recipient of a Senior Research Fellowship from the Council of Scientific and Industrial Research, India.

\section{REFERENCES}

1. Hafstrom, L., Rudenstam, C.M., Blomquist, E., Ingvar, C., Jonsson, P.E., Lagerlof, B., Lindholm, C., Ringborg, U., Westman, G., and Ostrup, L. (1991): Regional hyperthermic perfusion with melphalan after surgery for recurrent malignant melanoma of the extremities. J. Clin. Oncol., 9, 2091-2094.

2. Creagan, E.T. (1989): Regional and systemic strategies for metastatic malignant melanoma. Mayo Clin. Proc., 64, 852-860.

3. Habermalz, H.J., and Fischer, J.J. (1976): Radiation therapy of malignant melanoma. Cancer, 38, 2258-2262.

4. Hornsey, S. (1978): The relationship between oral dose, number of fractions and fraction size in the response of malignant melanoma in patients. Br. J. Cancer, 51, 905-909.

5. Strauss, A., Dritschilo, A., Nathanson, L., and Firo, A.J. (1981): Radiation therapy of malignant melanoma. Cancer, 48, 1262-1266.

6. Lobo, P.A., Liebner, E.J., Chao, J.J.H., and Kanji, A.M. (1981): Radiotherapy in the management of malignant melanoma. Int. J. Radiat. Oncol. Biol. Phys., 7, 21-26.

7. Doss, L.L., and Memula, N. (1982): The radioresponsiveness of melanoma. Int. J. Radiat. Oncol. Biol. Phys., 8, 1131-1134.

8. Perez, C.A., Nussbaum, G., Emami, B., and Vongerichten, D. (1983): Clinical results of irradiation combined with local hyperthermia. Cancer, 52, 1597-1603.

9. Overgaard, J., Von Der Maase, H., and Overgaard, M. (1985): A randomized study comparing two high dose per fraction radiation schedules in recurrent or metastatic malignant 
melanoma. Int. J. Radiat. Oncol. Biol. Phys., 11, 1837-1839.

10. Overgaard, J., Overgaard, M., Vejby-Hansen, P., and Von Der Maase, H. (1986): Some factors of importance in the radiation treatment of malignant melanoma. Radiother. Oncol., 5, 183-192.

11. Konefal, J.B., Emami, B., and Pilepich, M.V. (1987): Malignant melanoma: Analysis of dose fractionation in radiation therapy. Radiology, 164, 607-610.

12. Konefal, J.B., Emami, B., and Pilepich, M.V. (1988): Analysis of dose fractionation in the palliation of metastases from malignant melanoma. Cancer, 61, 243-246.

13. Ang, K.K., Byers, R.M., Peters, L.J., Maor, M.H., Wendt, C.D., Morrison, W.H., Hussey, D. H., and Goepfert, H. (1990): Regional radiotherapy as adjuvant treatment for head and neck malignant melanoma. Arch. Otolaryngol. Head Neck Surg., 116, 169-172.

14. Ben-Yosef, R., and Kapp, D.S. (1993): Prognostic factors in metastatic malignant melanoma treated with combined radiation and hyperthermia. Int. J. Hyperthermia, 9, 767-781.

15. Wheldon, T.E. (1979): Optimal scheduling for the radiotherapy of tumor cells possessing wide-shouldered survival curves. Br. J. Radiol., 52, 417-418.

16. Selby, P.J., and Courtenay, V.D. (1987): In vitro cellular radiosensitivity of human malignant melanoma. Int. J. Hyperthermia, 3, 483-501.

17. Bentzen, S.M., Overgaard, J., Thames, H.D., Overgaard, M., Vejby-Hansen, P., Von Der Maase, H., and Meder, H. (1989): Clinical radiobiology of malignant melanoma. Radiother. Oncol., 66, 169-182.

18. Anderson, R.L., and Kapp, D.S. (1990): Hyperthermia in cancer therapy: Current status. Med. J. Aust., 152, 310-315.

19. Overgaard, J., and Overgaard, M. (1987): Hyperthermia as an adjuvant to radiotherapy in the treatment of malignant melanoma. Int. J. Hyperthermia, 3, 483-501.

20. Emami, B., Perez, C.A., Konefal, J., Pilepich, M.V., Leybovich, L., Straube, W., Vongerichten, D., and Hederman, M.A. (1988): Thermoradiotherapy of malignant melanoma. Int J. Hyperthermia, 4, 373-381.

21. Shidnia, H., Hornback, N.B., Shen, R.E., and Yune, M. (1990): An overview of the role of radiation therapy and hyperthermia in treatment of malignant melanoma. Adv. Exp. Med. Biol., 267, 531-545.

22. Engelhardt, R. (1987): Hyperthermia and cancer. Recent Results Cancer Res., 104, 136-199.

23. Dahl, O. (1988): Hyperthermia and chemotherapy: Biology and clinical studies. Interaction of hyperthermia and chemotherapy. Recent Results Cancer Res., 107, 157-191.

24. Voight, H., and Kleeberg, U.R. (1984): PALA, vindesine and cisplatinum combination chemotherapy in advanced malignant melanoma. Cancer, 53, 2058-2062.

25. Abele, R., Bernheim, J., Cumps, E., Buyse, M., and Kenis, Y. (1981): Re-evaluation of the combination of CCNU, vincristine and bleomycin in the treatment of malignant melanoma. Cancer Treat. Rep., 65, 5, 505.

26. Cohen, J.M., Onhuma, T., and Ambinder, E.P. (1986): Lomustine, bleomycin and cisplatin in patients with metastatic malignant melanoma. Cancer Treat. Rep., 70, 688-691.

27. Thatcher, N., Lind, M., and Morgenstern, G. (1989): High dose, double alkylating agent chemotherapy with DTIC, melphalan, or ifosfamide and rescue for metastatic malignant melanoma. Cancer, 63, 1296-1302.

28. McClay, E.F., Mastrangelo, M.J., and Sprandio, J.D. (1989): The importance of tamoxifen to a cisplatin containing regimen in the treatment of metastatic melanoma. Cancer, $\mathbf{6 3}$, $1292-1295$.

29. Siegler, H.E., Lucas, V.S., Jr., and Pharm, B.S. (1980): DTIC, CCNU, bleomycin and vincristine (BOLD) in metastatic melanoma. Cancer, 46, 2546-2549.

30. Young, D.W., Lever, R.S., and English, J.S.C. (1985): The use of BELD combination chemotherapy (bleomycin, vindesine, $\mathrm{CCNU}$ and DTIC) in advanced malignant melanoma. Cancer, 55, 1879-1882.

31. York, R.M., and Foltz, A.T. (1988): Bleomycin, vincristine, lomustine and DTIC chemotherapy for metastatic melanoma. Cancer, 61, 2183-2186.

32. Lakhani, S., Selby, P., and Bliss, J.M. (1990): Chemotherapy for malignant melanoma: Combination and high doses produce more responses without survival benefit. $B r . J$.

Vol. 19, No. 3, 1995 
Cancer, 61, 330-334.

33. Yamada, K., Someya, T., and Shimada, S. (1984): Thermochemotherapy for malignant melanoma: Combination therapy of ACNU and hyperthermia in mice. J. Invest. Dermatol., 82, $180-184$.

34. Yamada, K., Someya, T., and Shimada, S. (1985): Thermochemotherapy for malignant melanoma: Overcoming heterogeneity in drug sensitivity. J. Invest. Dermatol., 85, 43-46.

35. Raaphorst, G.P., and Azzam, E.I. (1992): Response of transformed and normal mouse cell lines to anti-melanin compounds, hyperthermia and radiation. Pigm. Cell Res., 5, 25-29.

36. Vincent, V., Gomez, M., and Ochotorena, M.M. (1990): Thermochemotherapy for B16 melanoma: Combination therapy for hyperthermia, melphalan and CCNU in mice. Pigm. Cell Res., 3, 1-7.

37. Kirby, C., and Gregoriadis, G. (1984): Preparation of liposomes, in Liposomes-A Practical Approach, ed. by New, R.R.C., IRL Press, New York, pp. 33-103.

38. Bartlett, G.R.J. (1959): Phosphorus assay in column chromatography. J. Biol. Chem., 234, 466-468.

39. Conover, W.J. (1950): Practical Non Parametric Statistics, Oxford Press, New York.

40. Suit, H.D., and Greweck, L.E. (1979): Potential for hyperthermia and radiation therapy. Cancer Res., 39, 2290-2298.

41. Overgaard, J., and Nielsen, O.S. (1984): Influence of thermotolerance on the effect of multifractionated hyperthermia in a $\mathrm{C} 3 \mathrm{H}$ mammary carcinoma in vivo, in Hyperthermia Oncology, Vol. 1, ed. by Overgaard, J., Taylor and Francis, London, pp. 211-214.

42. Herman, T.S., Teicher, B.A., Jochelson, M., Clark, J., Svensson, G., and Coleman, C.N. (1988): Rationale for use of local hyperthermia, radiation therapy and selected anticancer drugs in locally advanced human malignancies. Int. J. Hyperthermia, 4, 143-158.

43. Frei, E., III (1985) Curative cancer chemotherapy. Cancer Res., 45, 6523-6537.

44. Hoffer, K.G. (1987): Heat potentiation of radiation damage versus radiation potentiation of heat damage. Radiat. Res., 110, 450-457.

45. Suit, H.D., and Greweck, L.E. (1979): Potential for hyperthermia and radiation therapy. Cancer Res., 39, 2290-2298.

46. Teicher, B.A., Lazo, J.S., and Sartorelli, A.C. (1981): Classification of antineoplastic agents by their selective toxicities towards oxygenated and hypoxic tumor cells. Cancer Res., $\mathbf{4 1 ,}$ $73-81$.

47. Teicher, B.A., Herman, T.S., and Holden, S.A. (1988): Combined modality therapy with bleomycin, hyperthermia and radiation. Cancer Res., 48, 6291-6297.

48. Yatvin, M.B. (1978): Design of liposomes for enhanced local release of drugs by hyperthermia. Science, 202, 1290-1293.

49. Yatvin, M.B., Muhlen-Siepen, H., Porschen, W., Weinstein, J.N., and Feinendegen, L.E. (1981): Selective delivery of liposome associated cis-diachlorodiammine platinum (II) by heat and its influence on tumor drug uptake and growth. Cancer Res., 41, 1602-1607.

50. Weinstein, J.N., Magin, R.L., Cysyk, R.L., and Zaharko, D.S. (1980): Treatment of solid L1210 murine tumors with local hyperthermia and temperature sensitive liposomes containing methatrexate. Cancer Res., 40, 1388-1395.

51. Nishimura, Y., Ono, K., Hiraoka, M., Mansunaga, S., Jo, S., Shibamoto, Y., Sasai, K., Abe, M., Iga, K., and Ogawa, Y. (1990): Treatment of murine SCC VII tumors with localized hyperthermia and temperature sensitive liposomes containing cisplatin. Radiat. Res., 122, $161-167$.

52. Overgaard, J., Radacic, M.M., and Grau, C. (1991): Interaction of hyperthermia and cis-diamminedichloroplatinum (II) alone or combined with radiation in a $\mathrm{C} 3 \mathrm{H}$ mammary carcinoma in vivo. Cancer Res., 51, 707-711. 